\title{
Study of Jojoba (Simmondsia chinensis) Oil by Gas Chromatography
}

Ahmed K Al-Ghamdi ${ }^{*}$, Thanaa A Elkholy ${ }^{2}$, Shahd Abuhelal ${ }^{3}$, Hatem Alabbadi ${ }^{4}$, Dina Qahwaji ${ }^{5}$, Hanaan Sobhy ${ }^{6}$, Nahlaa Khalefah ${ }^{6}$ and Mohammad Abu Hilal $^{7}$

${ }^{1}$ Department of Medical Laboratory Technology, Faculty of Applied Medical Sciences, King Abdulaziz University, Jeddah 21589, Saudi Arabia

${ }^{2}$ AlAzhar University, Cairo, Egypt

3Institute of Pharmaceutical Science, King's College London, Waterloo, London, SE1 9NH, UK

${ }^{4}$ King Abdulaziz University, University Hospital, KFMRC, Jeddah, Saudi Arabia

${ }^{5}$ Department of Clinical Nutrition, Faculty of Applied Medical Sciences, King Abdul-Aziz University, Jeddah, Saudi Arabia

${ }^{6}$ Head of Pharmacology Unit, Biochemical and Toxicology and Food Deficiency, King Abdul-Aziz University, Jeddah, Saudi Arabia

${ }^{7}$ Consultant Hepatobiliary and Pancreatic Surgery, Southampton University Hospital, Southampton SO16 6YD, UK

*Corresponding author: Al-Ghamdi AK, Department of Medical Laboratory Technology, Faculty of Applied Medical Sciences,King Abdulaziz University, Jeddah 21589, Saudi Arabia, Tel: +966 58023 2426; E-mail: aalghamdi@kau.edu.sa

Received: August 03, 2017; Accepted: August 16, 2017; Published: August 21, 2017

Copyright: (C) $2017 \mathrm{Al}$-Ghamdi AK, et al. This is an open-access article distributed under the terms of the Creative Commons Attribution License, which permits unrestricted use, distribution, and reproduction in any medium, provided the original author and source are credited.

\begin{abstract}
The oil of Simmondsia chinensis (Link) CK Schneid (Simmondsiaceae) has been traditionally used in ethnomedicine because of its unique chemical constituents. This study aims to analyze the components of Egyptian Jojoba Oil (JO) and assess the differences between the Egyptian JO and that found in other parts of the world. The fatty acids and sterols profiles will also be determined by Gas Chromatography (GC). Jojoba seeds were subjected to hot extraction by solvent (hexane) followed by cold pressing extraction.

Our results showed that the fatty acid Behenic acid methyl ester (C22:0) and Cis-13, 16 Docosadienoic acid methyl ester (C22:2) were in higher percentages within the Egyptian oil compared to JO found in other parts of the world. On the other hand, Egyptian oil was found to have lower percentage of the fatty acids; Eliadic acid, YLinolenic acid, Cis-8,11,14 Eieosatrienoic acid, and Lingocernic acid. Heneicosaoic acid was in much higher percentages within the Egyptian oil and the Egyptian JO does not contain Arachidic, Arachidonic Caprylic, Capric, lauric, Tridecanoic, Myristicor Palmitoleic acid. This study reports novel results clarifying the components of JO cultivated in Egypt under different environmental conditions to our knowledge such results have not been report before.
\end{abstract}

Keywords: Jojoba oil; Gas chromatography; Fatty acids

\section{Introduction}

Simmondsia chinensis, is the sole member the Simmondsiaceae's family. It is known as Jojoba, which originates from the deserts of USA. However, it is now planted in many other deserts across the world. In Egypt, it is known to be cultivated in the Ismailia desert.

$S$. chinensis is unique plant in many ways [1] and its importance was early noted by the by Native Americans.

Jojoba seeds are known to produce a colorless, odorless oil or liquid wax. This oil has a unique chemical structure within the plant world. Nearly $97 \%$ of the wax is composed of a straight chain monoester of C-20 and C-22 acids and alcohols with two double bonds.

The acids have been identified as a mixture of cis-11-eicosenoic (C-20) and cis-13-docosenoic (C-22, erucic). The alcohols have been identified as mixtures of cis-11-eicosenol, cis-13-docosenol and cis-15tetracosenol (C-24). Sterols and stanols (around $0.5 \%$ total) are mainly represented by; campesterol, stigmasterol, sitosterol, cholesterol and avenasterol [2-4] along with some traces of triglyceride [5] and different tocopherols, such as $\alpha$-tocopherol [4].

Furthermore, groups of nitrile glycosides known as simmondsin's compounds (10-20\%) have also been identified [5,6]. Those simmondsins are considered as strange nitrile glycosides and cannot be compared to most nitrile glycosides found in plants [7]. It also contains phospholipids [2] and oligosaccharides [8].

Of more than 250,000 identified plant species, Jojoba is the only plant which produces significant quantities of liquid wax esters like the natural restorative esters produced by human sebaceous glands (sebum). Hence, it can be used as natural emollient for all skin types and hair. The wax is stable and resistant to both oxidation and rancidity [9]. Therefore, JO is used as a carrier substance for oxidation sensitive substances such as vitamin A [10]. In addition, Jojoba liquid wax is useful in the stabilization of penicillin products. In fact, JO, has been shown to be the finest liquid wax for this purpose [11]. Moreover, JO is used as carrier oil for essential oils in aromatherapy and massage therapy [12]. All this has attracted huge research interest leading to a number of quantitative and qualitative analyses performed interested researchers [4].

The purpose of this work is to study the chemical constituents of Jojoba wax, Egyptian cultivated $S$. chinensis. To our knowledge, this is the first work investigating similar parameters of the JO in Egypt. 


\section{Materials and Methods}

\section{Materials}

Jojoba oil: Three heaps of Jojoba seeds (season 2015) from different sites were kindly supplied by the farm affiliated to the Egyptian Natural Oil Co., Cairo, Egypt (season 2015).

Authentic samples: Standard sterols (campe, stigma, b-sito, isofuco-, 7-stigma-and avena-sterols); fatty acids methyl esters (C16-C24 saturated and unsaturated) and cetyl alcohol were purchased from Sigma Company.

Gas Chromatography analysis (GC): [(GC; HP Hewlett Packard 5890 series II-USA, MS; Mass selective detector HP Hewlett Packard 5972 series-USA) and Wiley Registry of Mass Spectral Data (Chemical data library) (1995)-Wiley-UK] was carried out in the environmental instrument lab and environmental labs testing division at the RSC.

\section{Methods}

Preparation of jojoba oil: After a complete removal of all seed's teats, cold pressing technique was used for extracting the liquid wax and other related compounds. This method is based on a hydraulic presser machine designed specifically for this purpose in the Jojoba's coldpressing unit.

Gas Chromatography (GC) for fatty acids analysis: For determination of fatty acids in JO, obtained from the seeds by hot reflux and cold pressing extraction methods, a previously reported and validated method was used (International Olive Council). The method (stated below) describes a procedure for determining the individual and total fatty acids content of by capillary column gas chromatography [13] through preparation of the fatty acids methyl esters from JO by:

1. Seeds extracts were dissolved in a chloroform methanol saline mixture of (8:4:3), while final concentration was $0.33 \mathrm{~g} / \mathrm{ml}$.

2. Extracts were homogenized in the solvent mixture. However, in some cases oil was dissolved in methanol up to $0.1 \mathrm{~g} / \mathrm{ml}$, then the concentration was adjusted by chloroform to $0.33 \mathrm{~g} / \mathrm{ml}$.

3. Extraction was performed up to three times to remove all the lipids.

Methylations reaction [14] was performed by adding; $1.5 \mathrm{ml}$ methanol, 150 micro-litter Methanolic-HCL 8\%. The reaction was left to complete over $14-16$ hours at $45^{\circ} \mathrm{C}$. GC samples were dissolved in hexane and $1 \mu \mathrm{l}$ was injected for analysis using GC instrument model HP5942, Column HP-5: $30 \mathrm{~m} \times 0.25 \mathrm{~nm} \times 0.20 \mathrm{~nm}$, Carrier gas nitrogen $1 \mathrm{ml} / \mathrm{sec}$, Injector temp: $260^{\circ} \mathrm{C}$, Detector temp: $260^{\circ} \mathrm{C}$, samples were ran for 45 minutes total run time. Heating was programmed at $140^{\circ} \mathrm{C}$ for 5 minutes then was increased to $260^{\circ} \mathrm{C}$ at a velocity of $3^{\circ} \mathrm{C}$ per minute. Results were compared with a standard using chemi-station program.

\section{Results and Discussion}

\section{Gas Chromatography (GC) for fatty acids}

The results are shown in Table 1 . The procedure was performed in triplicate.

The results, based on GC analyses of previously studied Jordanian JO [4] indicated that the oil contains fatty acids of carbon atoms from $14^{\circ} \mathrm{C}$ to $24^{\circ} \mathrm{C}$ (saturated and unsaturated). Furthermore, the main fatty acids identified in the JO were Heneicosanoic acid (21:0), Behenic acid (22:0), Cis-13 and 16 Docosadienoic acid (22:2). This is in line with previous reports $[4,15]$.

It was also noticed that the fatty acid Cis-11 Eicosaenoic acid (20:1) was in higher concentrations within the Egyptian wax compared to JO from around the world. In contrast, the fatty acids heptadecanoic acid (17:0), Eliadic acid (18:1n9t), Cis-8,11, 14 Eieosatrienoic acid (20:3) and Lingocernic acid (24:0) were in lower concentration within the Egyptian oil compared to JO from around the world. This became clear after comparing our results for Egyptian JO with studies testing Jordanian JO $[4,15]$.

\begin{tabular}{|c|c|}
\hline Fatty acids & Concentration $(\mu \mathrm{g} / \mathrm{ml})$ \\
\hline $\mathrm{C} 4: 0$ & $2.57650 \mathrm{e}^{-2}$ \\
\hline C6:0 & $7.516622 \mathrm{e}^{-1}$ \\
\hline C8:0 & ---------" \\
\hline C10:0 & ---------- \\
\hline C11:0 & --------- \\
\hline C12:0 & ---------- \\
\hline C13:0 & --------- \\
\hline C14:0 & --------- \\
\hline C14:1 & --------- \\
\hline C15:0 & --------- \\
\hline C15:1 & $3.78618 \mathrm{e}^{-2}$ \\
\hline C16:0 & $3.48415 \mathrm{e}^{-2}$ \\
\hline C16:1 & --------- \\
\hline C17:0 & $1.4872 e^{-2}$ \\
\hline C17:1 & $8.0024 \mathrm{e}^{-2}$ \\
\hline C18:0 & $5.78082 e^{-2}$ \\
\hline C18:1n9t & $1.00307 \mathrm{e}^{-2}$ \\
\hline $\mathrm{C} 18: 1 \mathrm{n} 9 \mathrm{c}$ & $4.29783 e^{-1}$ \\
\hline C18:2n6t & 2.35591 \\
\hline $\mathrm{C} 18 \mathrm{an} 6 \mathrm{c}$ & 4.13070 \\
\hline $\mathrm{C} 20: 0$ & -------- \\
\hline $\mathrm{C} 20: 3 \mathrm{n} 6$ & $1.13692 \mathrm{e}^{-1}$ \\
\hline C18:3n6 & $1.02111 \mathrm{e}^{-2}$ \\
\hline $\mathrm{C} 22: 2$ & 13.1111219 \\
\hline C20:1 & 24.28284 \\
\hline C18:3n3 & $2.07436 \mathrm{e}^{-2}$ \\
\hline $\mathrm{C} 21: 0$ & 19.24169 \\
\hline $\mathrm{C} 20: 2$ & $8.78022 \mathrm{e}^{-2}$ \\
\hline $\mathrm{C} 22: 0$ & 13.54594 \\
\hline
\end{tabular}


Citation: Al-Ghamdi AK, Elkholy TA, Abuhelal S, Alabbadi H, Qahwaji D, et al. (2017) Study of Jojoba (Simmondsia chinensis) Oil by Gas Chromatography. Nat Prod Chem Res 5: 282. doi:10.4172/2329-6836.1000282

Page 3 of 3

\begin{tabular}{|l|l|}
\hline $\mathrm{C} 22: 1 \mathrm{n} 9$ & $4.70928 \mathrm{e}^{-2}$ \\
\hline $\mathrm{C} 20: 3 \mathrm{n} 3$ & 5.686364 \\
\hline $\mathrm{C} 23: 0$ & 3.94414 \\
\hline C20:4n6 & ------- \\
\hline C24:0 & 1.14591 \\
\hline C20:5n3 & $2.76868 \mathrm{e}^{-1}$ \\
\hline C24:1 & -------- \\
\hline C22:6 & $7.9140 \mathrm{e}^{-1}$ \\
\hline *concentration was not detected \\
\hline
\end{tabular}

3. Tada A, Jin ZL, Sugimoto N, Sato K, Yamazaki T, et al. (2005) Analysis of the Constituents in Jojoba Wax Used as a Food Additive by LC/MS/MS. J Food Hyg Soc 46: 198-204.

4. El-Mallah MH, El-Shami SM (2009) Investigation of Liquid Wax Components of Egyptian Jojoba Seeds. J Oleo Sci 58: 543-548.

5. Van Boven M, Holser RA, Cokelaere M, Decuypere E, Govaerts C, et al. (2000) Characterization of Triglycerides Isolated from Jojoba oil. JAOCS 77: 1325-1329.

6. Laszlo Joseph A, Compton David L, Liang LX (2006) Feruloyl esterase hydrolysis and recovery of ferulic acid from jojoba meal. Indus Crops and Prod 23: 46-53.

7. Allen Joselyn J (1997) Application of colorimetric assay for the determination of cyanide in deoiled jojoba meal. Master's Theses in Nutritional Science, The Faculty of Nutrition and Food Science, San Jose State University, USA.

8. Hantus S, Pauly M, Darvill AG, Albersheim P, York WS (1997) Structural characterization of novel L-galactose-containing oligosaccharide subunits of jojoba seed xyloglucans. Carbohydr Res 304: 11-20.

\section{Conclusion}

Egyptian JO is different from other JO, it is a rich source of fatty acids and triglycerides and have great potentials to be used in different fields such as the cosmetic and pharmaceutical industry.

\section{Acknowledgement}

This Project was funded by Deanship of Scientific Research (DSR), King Abdulaziz University, Jeddah, under grant no: 348/3/341 RG.

\section{References}

1. Howard Scott G (1958) The Natural History of Jojoba (Simmondsia chinensis) and its cultural aspects. Econom Bot 12: 261-295.

2. Léon F, Van Boven M, de Witte P, Busson R, Cokelaere M (2004) Isolation and identification of molecular species of phosphatidylcholine and lysophosphatidylcholine from jojoba seed meal (Simmondsia chinensis). J Agric Food Chem 52: 1207-1211.

9. Mishra AK, Mishra A, Chattopadhyay P (2011) Herbal Cosmeceuticals for Photoprotection from Ultraviolet B Radiation: A Review. Tropical J Pharmaceu Res 10: 351-360.

10. Gruenwald Joerg G (1998) PDR for Herbal Medicine. (1st edn), USA, Medical Economics Company.

11. Daugherty PM, Sineath HH, Wastler TA (2012) Industrial raw materials of plant origin (IV) A survey of Simmondsia chinensis (Jojoba). Econ Bot 12: 296-304.

12. Buckle Jane B (2007) Clinical Aromatherapy. (2nd edn), China, Churchill Livingstone.

13. Folch J, Lees M, Stanley GHS (1957) Increased cholesterol content of erythrocyte and brain membranes in ethanol-tolerant mice. J Biol Chem 226: 497-509.

14. Nelson GJ (1991) Analyses of Oils and Fats. American Oil Chemists' Soc., Champaign, pp: 20-59.

15. Al-Qizwini H, Al-Khateeb E, Mhaidat NM (2014) Study of Jordanian Jojoba (simmondsia chinensis) liquid wax by GC and GC/MS. Europ Sci J 10: $1857-7881$. 